\title{
Ventricular Pacing of Conventional Pacemakers in the Era of CRT
}

\author{
Silas dos Santos Galvão Filho \\ Centro Avançado de Ritmologia e Eletrofisiologia (CARE), São Paulo, SP - Brazil \\ Short Editorial related to the article: Efficacy, Safety, and Performance of Isolated Left vs. Right Ventricular Pacing in Patients with \\ Bradyarrhythmias: A Randomized Controlled Trial
}

With the advent of cardiac resynchronization therapy (CRT), and the awareness of the impairment of ventricular systolic function caused by intraventricular conduction disorders, especially left bundle branch block, after more than 50 years of routine use, conventional right univentricular artificial cardiac pacing, particularly in its classical site - the apical region - is now being questioned. In fact, conventional right univentricular pacing usually generates a large QRS (often greater than $150 \mathrm{~ms}$ ), with electrocardiographic pattern of left bundle branch block - more significant signs for the diagnosis of ventricular dyssynchrony that may require CRT. ${ }^{1}$

Some studies have shown impairment of right univentricular pacing in patients with pacemakers compared to normal ventricular activation, ${ }^{2-4}$ which prompted the development of algorithms of minimal ventricular pacing, favoring exclusive atrial pacing in currently available dual-chamber pacemakers, which have shown some benefits. However, when the reestablishment of heart rate requires ventricular pacing (in cases of AV blocks), these algorithms cannot be used. Other studies have shown deterioration of ventricular systolic function after initiation of right univentricular pacing. ${ }^{5,6}$ In order to minimize any impairment of right univentricular pacing in cases where it is necessary, multiple pacing sites have been tried: ${ }^{7}$ (outflow tract, mid-septal, inferior-septal, etc.) and, although no further evidence has been achieved, today, mid-septal pacing is the most commonly method

\section{Keywords}

Cardiac Pacing,Artificial/methods; Bradycardia; Arrhythmias,Cardiac; Pacemaker, Artificial/utilization; Remodeling Atrial.

Mailing Address: Silas dos Santos Galvão Filho •

Rua Martiniano de Carvalho, 864/702. Postal Code 01321-000, São Paulo, SP - Brazil

E-mail: sdsantos@uol.com.br

DOI: $10.5935 / a b c .20190074$ in conventional pacemaker implants, to the detriment of apical pacing.

Special Hisian pacing presents good results ${ }^{8}$ and has been shown to be the best site of univentricular pacing in terms of activation synchrony. However, some problems, such as: high pacing thresholds, low endocavitary potentials, oversensing of atrial potential, and implantation difficulties at this site, still need to be considered for this type of ventricular pacing to be routinely used in patients with recommendation of pacemaker.

Exclusive left ventricular pacing has been proposed as an alternative to $\mathrm{CRT}$ in patients with $\mathrm{CHF}$ requiring ventricular pacing, ${ }^{9}$ and did not deliver any considerable benefits in these patients. The manuscript "Efficacy, Safety, and Performance of Left vs. Right Ventricular Pacing in Patients with Bradyarrhythmias: A Randomized Clinical Trial"10 is a well-designed original study that compared these two types of pacing in patients with preserved cardiac function and recommendation for conventional pacemaker. The findings of that study showed low success rate and safety in the implantation of LV electrode via the coronary sinus, contradicting the initial assumption and questioning the appropriateness of proposing left ventricular pacing via the coronary sinus as an option for conventional endocardial right ventricular pacing in patients with recommendation of pacemaker. These findings, however, have been impaired by the small number of patients included and the use of a electrode for LV pacing, which is highly associated with low-performance and complication, not reproducing much better results in the literature for this type of procedure. ${ }^{11,12}$

Although it is contested, especially in patients with cardiac systolic dysfunction, where some guidelines recommend that preference should be given to biventricular pacing, ${ }^{1}$ right univentricular pacing persists and is routinely used in patients with recommendation of conventional pacemakers who have preserved ventricular function, and there is no consensus as to the best site of pacing. However, preference is given to the septal region. 


\section{Short Editorial}

\section{References}

1. Ponikowski P, Voors AA, Anker SD, Bueno H, Cleland JG, Coats AJ, at al. 2016 ESC Guidelines for the diagnosis and treatment of acute and chronic heart failure: The Task Force for the diagnosis and treatment of acute and chronic heart failure of the European Society of Cardiology (ESC). Developed with the special contribution of the Heart Failure Association (HFA) of the ESC. Eur J Heart Fail. 2016;18(8):891-975.

2. Wilkoff BL, Cook JR, Cook JR, Epstein AE, Greene HL, Halltrom AP, et al. Dual-chamber pacing or ventricular backup pacing in patients with an implantable defibrillator: The Dual-chamber and VVI Implantable Defibrilator (DAVID) trial. JAMA. 2002;288(24):3115-23.

3. Sweeney MO, Hellkamp AS, Ellenbogen KA, Greenspon AJ, Freedman RA, Lee KL, et al. MOde Selection Trial Investigators. Adverse effect of ventricular pacing on heart failure and atrial fibrillation among patients with normal baseline QRS duration in a clinical trial of pacemaker therapy for sinus node disfunction. Circulation.2003;17;107(23):2932-7.

4. Nielsen JC, Kristensen L, Andersen HR, Mortensen PT, Pedersen OL, Pedersen AK. A randomized comparison of atrial and dual-chamber pacing in 177 consecutive patients with sick sinus syndrome: echocardiographic and clinical outcome. J Am Coll Cardiol. 2003;20;42(4):614-23.

5. Pastore G, Noventa F, Piovesana P, Cazzin R, Aggio S, Verlato R, et al. Left ventricular dyssynchrony resulting from right ventricular apical pacing: relevance of baseline assessment. Pacing Clin Electrophysiol. 2008;31(11):1456-62.

6. Khurshid S, Epstein AE, Verdino RJ, Lin D, Goldberg LR, Marchlinski $\mathrm{FE}$, et al. Incidence and predictors of right ventricular pacing-induced cardiomyopathy. Heart Rhythm. 2014;11(9):1619-25.
7. Kaye GC, Linker NJ, Marwick TH, Pollock L, Graham L, Pouliot E, et al. Effect of right ventricular pacing lead site on left ventricular function in patients with high-grade atrioventricular block: results of the Protect-Pace study. Eur Heart J. 2015;36(14):856-62.

8. Vijayaraman P, Chung MK, Dandamudi G, Upadhyay GA, Krishnan K, Crossley G, et al. ACC's Electrophysiology Council. His Bundle Pacing. J Am Coll Cardiol. 2018. 21;72(8):927-47.

9. LiangY,PanW,SuY,GeJ. Meta-analysis of randomized controlled trials comparing isolated left ventricular and biventricular pacing in patients with chronic heart failure. Am J Cardiol. 2011;108(8):1160-5.

10. Crevelari ES, da Silva KR, Albertini CMM, Vieira MLC, Martinelli Filho M, Costa R. Eficácia, Segurança e Desempenho da Estimulação Ventricular Esquerda versus Direita em Pacientes com Bradiarritmias: Ensaio Clínico Randomizado. Arq Bras Cardiol. 2019; 112(4):410-421.

11. Cleland JG, Daubert JC, Erdmann E, Freemantle N, Gras D, Kappenberger $\mathrm{L}$, et al. Cardiac Resynchronization-Heart Failure (CARE-HF) Study Investigators. The effect of cardiac resynchronization on morbidity and mortality in heart failure. N Engl J Med. 2005. 14;352(15):1539-49.

12. Linde C, Abraham WT, Gold MR, St John Sutton M, Ghio S, Daubert C REVERSE (REsynchronization reVErses Remodeling in Systolic left vEntricular dysfunction) Study Group. Randomized trial of cardiac resynchronization in mildly symptomatic heart failure patients and in asymptomatic patients with left ventricular dysfunction and previous heart failure symptoms. J Am Coll Cardiol. 2008;52(23):1834-43. 